\title{
GPS phase scintillation and proxy index at high latitudes during a moderate geomagnetic storm
}

\author{
P. Prikryl ${ }^{1}$, R. Ghoddousi-Fard ${ }^{2}$, B. S. R. Kunduri ${ }^{3}$, E. G. Thomas ${ }^{3}$, A. J. Coster ${ }^{4}$, P. T. Jayachandran ${ }^{5}$, \\ E. Spanswick ${ }^{6}$, and D. W. Danskin ${ }^{7}$ \\ ${ }^{1}$ Communications Research Centre, Ottawa, ON, Canada \\ ${ }^{2}$ Geodetic Survey Division, Natural Resources Canada, Ottawa, ON, Canada \\ ${ }^{3}$ Bradley Department of Electrical and Computer Engineering, Virginia Tech, Blacksburg, VA, USA \\ ${ }^{4}$ Haystack Observatory, Massachusetts Institute of Technology, Westford, MA, USA \\ ${ }^{5}$ Physics Dept, University of New Brunswick, Fredericton, NB, Canada \\ ${ }^{6}$ Department of Physics and Astronomy, University of Calgary, AB, Canada \\ ${ }^{7}$ Geomagnetic Laboratory, Natural Resources Canada, Ottawa, ON, Canada
}

Correspondence to: P. Prikryl (paul.prikryl@crc.ca)

Received: 20 December 2012 - Revised: 5 April 2013 - Accepted: 8 April 2013 - Published: 6 May 2013

\begin{abstract}
The amplitude and phase scintillation indices are customarily obtained by specialised GPS Ionospheric Scintillation and TEC Monitors (GISTMs) from L1 signal recorded at the rate of $50 \mathrm{~Hz}$. The scintillation indices $S_{4}$ and $\sigma_{\Phi}$ are stored in real time from an array of high-rate scintillation receivers of the Canadian High Arctic Ionospheric Network (CHAIN). Ionospheric phase scintillation was observed at high latitudes during a moderate geomagnetic storm $(\mathrm{Dst}=-61 \mathrm{nT})$ that was caused by a moderate solar wind plasma stream compounded with the impact of two coronal mass ejections. The most intense phase scintillation $\left(\sigma_{\Phi}\right.$ $\sim 1 \mathrm{rad}$ ) occurred in the cusp and the polar cap where it was co-located with a strong ionospheric convection, an extended tongue of ionisation and dense polar cap patches that were observed with ionosondes and HF radars. At sub-auroral latitudes, a sub-auroral polarisation stream that was observed by mid-latitude radars was associated with weak scintillation (defined arbitrarily as $\sigma_{\Phi}<0.5 \mathrm{rad}$ ). In the auroral zone, moderate scintillation coincided with auroral breakups observed by an all-sky imager, a riometer and a magnetometer in Yellowknife. To overcome the limited geographic coverage by GISTMs other GNSS data sampled at $1 \mathrm{~Hz}$ can be used to obtain scintillation proxy indices. In this study, a phase scintillation proxy index (delta phase rate, DPR) is obtained from $1-\mathrm{Hz}$ data from CHAIN and other GPS receivers. The $50-\mathrm{Hz}$ and $1-\mathrm{Hz}$ phase scintillation indices are correlated. The percentage occurrences of $\sigma_{\Phi}>0.1 \mathrm{rad}$ and
\end{abstract}

DPR $>2 \mathrm{~mm} \mathrm{~s}^{-1}$, both mapped as a function of magnetic latitude and magnetic local time, are very similar.

Keywords. Ionosphere (Ionospheric irregularities) - Magnetospheric physics (Storms and substorms) - Radio science (Space and satellite communication)

\section{Introduction}

The high-latitude ionosphere dynamics is largely driven by coupling processes between the solar wind and the Earth's magnetic field and can be viewed as footprints in the ionosphere. These include ionospheric convection, energetic particle precipitation causing auroras, and ionospheric irregularities of various scale sizes. The ionospheric irregularities cause rapid fluctuations of radio signal amplitude and phase, called scintillation, which can affect the performance of radio communication and navigation systems.

Scintillation indices, $S_{4}$ and $\sigma_{\Phi}$, are widely used as a measure of amplitude and phase scintillation, respectively (Basu et al., 1985; Du et al., 2001; Kintner et al., 2007; Béniguel et al., 2009; Spogli et al., 2009; Prikryl et al., 2011). The $S_{4}$-index is the standard deviation of the received power normalised by its mean value, and the phase scintillation index $\sigma_{\Phi}$ is the standard deviation of the detrended L1 phase using a filter in the receiver with a cutoff frequency. These indices are usually obtained from high-rate (typically $50 \mathrm{~Hz}$ ) 


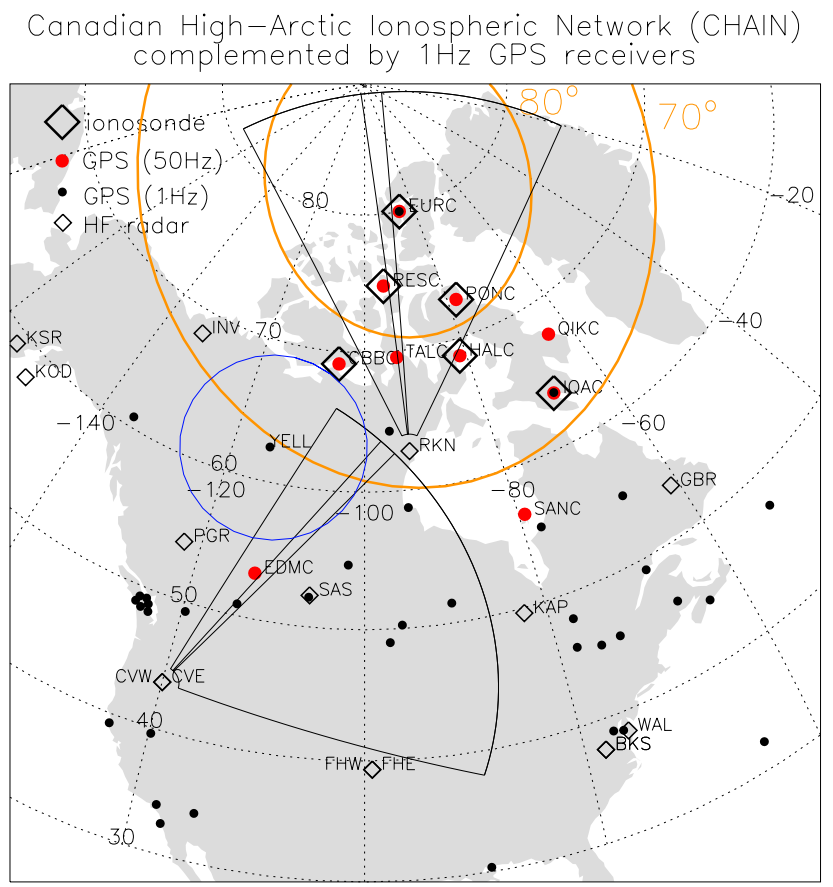

Fig. 1. Canadian High Arctic Ionospheric Network (CHAIN) complemented by other GPS receivers recording at sampling rate of $1 \mathrm{~Hz}$. Fields of view of an all-sky imager in Yellowknife and SuperDARN radars in Rankin Inlet and Christmas Valley East with beams 6 and 3, respectively, are shown. Locations of other SuperDARN radars are indicated by diamonds. The corrected geomagnetic (CGM) latitudes 70 and $80^{\circ}$, in yellow, are superposed over the geographic grid in dotted line.

data obtained by specialised GPS Ionospheric Scintillation and TEC Monitors (GISTMs), which provide only sparse geographic coverage at present. The TEC rate can be used as an index to monitor ionospheric irregularities (see e.g., Pi et al., 1997; Beach and Kintner, 1999; Jakowski et al., 2012). $S_{4}$ scintillation index proxies have been used at low latitudes (Du et al., 2001; Dandekar and Groves, 2004). In this paper, a proxy for $\sigma_{\Phi}$ is obtained from GPS receivers recording $1-\mathrm{Hz}$ data to complement availability of $\sigma_{\Phi}$ that is often enhanced at high latitudes (Prikryl et al., 2011, 2013).

Observations of response in the northern high-latitude ionosphere to a moderate geomagnetic storm are presented. A variety of data are collected with an array of instruments, including HF radars, ionosondes, riometers, magnetometers, and an all-sky imager, to support a network of GPS receivers. The most intense scintillation was observed in the cusp and the polar cap, associated with a tongue of ionisation (TOI), while moderate-to-weak scintillation was associated with auroral breakups and a sub-auroral polarisation stream (SAPS).
Table 1. Geographic latitudes and longitudes of stations.

\begin{tabular}{|c|c|c|c|c|c|}
\hline \multicolumn{6}{|c|}{ CHAIN } \\
\hline EURC & 79.99 & 274.10 & RESC & 74.75 & 265.00 \\
\hline PONC & 72.69 & 282.04 & CBBC & 69.12 & 254.97 \\
\hline TALC & 69.54 & 266.44 & HALC & 68.78 & 278.74 \\
\hline QIKC & 67.53 & 295.97 & IQAC & 63.73 & 291.46 \\
\hline SANC & 56.54 & 280.77 & EDMC & 53.35 & 247.03 \\
\hline \multicolumn{6}{|c|}{ Other GPS receivers (sampled at $1 \mathrm{~Hz}$ ) } \\
\hline BAIE & 49.19 & 291.74 & BAKE & 64.32 & 264.00 \\
\hline KUUJ & 55.28 & 282.25 & PICL & 51.48 & 269.84 \\
\hline VALD & 48.10 & 282.44 & HLFX & 44.68 & 296.39 \\
\hline ALGO & 45.96 & 281.93 & CHUR & 58.76 & 265.91 \\
\hline EUR2 & 79.99 & 274.06 & FRDN & 45.93 & 293.34 \\
\hline NRC1 & 45.45 & 284.38 & PRDS & 50.87 & 245.71 \\
\hline $\mathrm{SCH} 2$ & 54.83 & 293.17 & STJO & 47.60 & 307.19 \\
\hline WHIT & 60.75 & 224.78 & WINN & 49.01 & 262.74 \\
\hline YELL & 62.48 & 245.52 & ALBH & 48.39 & 236.51 \\
\hline DR2O & 49.32 & 240.37 & DUBO & 50.26 & 264.13 \\
\hline FLIN & 54.73 & 258.02 & NANO & 49.29 & 235.91 \\
\hline SASK & 52.20 & 253.60 & PMTL & 45.56 & 286.48 \\
\hline IQAL & 63.76 & 291.49 & BAMF & 48.84 & 234.86 \\
\hline PTAL & 49.26 & 235.14 & PTRF & 48.54 & 235.59 \\
\hline $\mathrm{SC} 04$ & 48.92 & 36.30 & & & \\
\hline
\end{tabular}

\section{Instruments and methods}

At the time of the data studied, the Canadian High Arctic Ionospheric Network (CHAIN) (Jayachandran et al., 2009) consisted of ten specialised GPS receivers and six Canadian Advanced Digital Ionosondes (CADIs) distributed in the auroral oval and the polar cap (Fig. 1). The locations of CHAIN stations that are shown at chain.physics.unb.ca are also included in Table 1. The receivers are the GISTM GSV 4004B (Van Dierendonck and Arbesser-Rastburg, 2004). A GISTM consists of a NovAtel OEM4 dual frequency receiver with special firmware specifically configured to measure and record power and phase of the GPS L1 signal at high sampling rate $(50 \mathrm{~Hz})$. The GSV 4004B can also automatically compute and record $S_{4}$ and $\sigma_{\Phi}$ indices; one-minute values are used in this paper. Each receiver is capable of tracking and reporting scintillation and total electron content (TEC) measurements simultaneously from up to 10 GPS satellites in view.

GPS stations with $1-\mathrm{Hz}$ sampling rate in North America are used to complement the CHAIN stations scintillation measurements. Table 1 shows stations with CGM latitude exceeding $50^{\circ} \mathrm{N}$ that are used in this study. A proxy index (delta phase rate, DPR) (Ghoddousi-Fard and Lahaye, 2012) is based on phase rate variations in units of $\mathrm{mm} \mathrm{s}^{-1}$ since it is obtained as a difference between ionospheric phase delays encountered by GPS phase measurements over two consecutive epochs $1 \mathrm{~s}$ apart, averaged over $30 \mathrm{~s}$ as follows: 
$\mathrm{DPR}=\frac{\sum_{i=0}^{n} \psi_{i}}{n}$

where

$\psi_{i}=\frac{\varphi_{\mathrm{g}}^{t_{i+1}}-\varphi_{\mathrm{g}}^{t_{i}}}{t_{i+1}-t_{i}}$

where $t_{i}$ and $t_{i+1}$ are two consecutive epochs and $\varphi_{\mathrm{g}}=$ $\lambda_{1} L_{1}-\lambda_{2} L_{2}$ where $L_{1}$ and $L_{2}$ are the GPS carrier phase measurements, and $\lambda_{1}$ and $\lambda_{2}$ are their respective wavelengths.

For direct comparison between the one-minute phase scintillation index $\sigma_{\Phi}$ and DPR proxy index we use the absolute value of DPR over $60 \mathrm{~s}(n=60)$. Because of the undersampling at $1 \mathrm{~Hz}$, this proxy index does not capture the rapid changes of the phase and, therefore, is not valid for strong scintillation (Rino, 1979; Yeh and Liu, 1982).

Solar wind data were obtained from the Goddard Space Flight Center Space Physics Data Facility OMNIWeb (http: //omniweb.gsfc.nasa.gov/). Solar wind magnetic field and plasma parameters from OMNIWeb dataset combine available solar wind monitor data projected to the nose of the Earth's bow shock. To identify geo-effective interplanetary coronal mass ejections (ICMEs) we use a catalogue of nearEarth ICMEs (Richardson and Cane, 2010) that is updated at http://www.srl.caltech.edu/ACE/ASC/DATA/level3.

The GISTM arrays are supported by radars, optical instruments and magnetometers of the Canadian Geospace Monitoring (CGSM) programme (Liu, 2005) and magnetometer data provided by NRCan Geomagnetic Laboratory (http: //www.spaceweather.ca). The Northern Solar Terrestrial Array (NORSTAR) (Donovan et al., 2003) is an optical and radio facility designed to remotely sense auroral precipitation on a continental scale. NORSTAR consists of CCDbased All-Sky Imagers (ASIs), Meridian Scanning Photometers (MSPs), and riometers.

The Super Dual Auroral Radar Network (SuperDARN) is a network of coherent-backscatter HF radars with a collective field-of-view that covers a large fraction of the high-latitude ionosphere (Greenwald et al., 1995; Chisham et al., 2007). The radars transmit at frequencies $8-20 \mathrm{MHz}$ along 16-24 contiguous, successively swept azimuthal beams, each of which is gated into 75-115 range bins. The bins are typically $45 \mathrm{~km}$ long in standard operations, and the dwell time for each beam is usually 3 or $7 \mathrm{~s}$. A full 16-beam scan with successive beams separated by $3.24^{\circ}$ covers $\sim 52^{\circ}$ in azimuth every 1 or $2 \mathrm{~min}$. Several quantities including the line-ofsight Doppler velocity, spectral width and backscatter power from field-aligned ionospheric (FAI) plasma irregularities are routinely measured. The PolarDARN component of SuperDARN covers a large portion of the polar ionosphere in the Northern Hemisphere. The mid-latitude component of SuperDARN has been expanded since 2009 owing to NSFfunded construction of several radars under the Mid-Sized
Infrastructure (MSI) programme (see, e.g., Clausen et al., 2012). By the time of the radar data that are presented in this paper were collected, the mid-latitude SuperDARN coverage reached across North America in an unbroken chain of interlocking radar field-of-view.

The GPS TEC maps are obtained using the plotting tools (Thomas et al., 2013) available online (http://vt.superdarn. org) with the TEC data downloaded from the Madrigal database. The Madrigal database system is an open-source project based at MIT Haystack Observatory. It is a robust World Wide Web based system, capable of managing and serving archival and real-time data, in a variety of formats, from a wide range of upper atmospheric science instruments. It allows for data files to be easily exchanged between sites, although data at each Madrigal site is locally controlled and can be updated at any time, but shared metadata between Madrigal sites allow searching of all Madrigal sites at once. It is used by most incoherent scatter radar facilities around the world to allow access to their data over the web. Built into Madrigal are a large number of web services designed for atmospheric scientists, such as field line tracing and simple access to geophysical parameters. GPS processing tools have also been developed at MIT Haystack that allow for automated processing of total electron content data from more than 2000 GPS receivers available online.

The TEC data are stored in the Madrigal data base in 1 degree by 1 degree by $5 \mathrm{~min}$ bins where data are available. The TEC data were processed using MIT Automated Processing of GPS (MAPGPS) that has been developed to automate the processing of GPS data into global TEC maps (Rideout and Coster, 2006). A standard spatiotemporal median filtering technique is applied using TEC observations from three intervals to generate a single TEC map. The primary modification involved an improvement in the handling of errors used in the TEC processing. Errors are now tracked throughout the software, and random and correlated receiver bias errors described above are handled separately. This allows for optimal estimation of binned measurements using weighted averages and allows error values to be calculated independently for each binned measurement. The bin-to-bin variability in the TEC measurements was greatly reduced using this approach.

\section{Solar wind conditions and the ionospheric response at high latitudes}

A moderate solar wind plasma stream from a weak coronal hole compounded with two ICMEs disturbed the Earth magnetosphere and ionosphere from 30 October to 5 November 2011. Figure 2 shows 5-min averages of the solar wind velocity, $V_{\mathrm{sw}}$, the IMF components $B_{\mathrm{y}}$ and $B_{\mathrm{z}}$, total magnitude, $B$, and proton density, $n_{\mathrm{p}}$, from the OMNI dataset projected to subsolar bow shock. The upstream shocks of two ICMEs are indicated by vertical dotted lines. The first ICME approximately coincided with a plasma stream interface in 


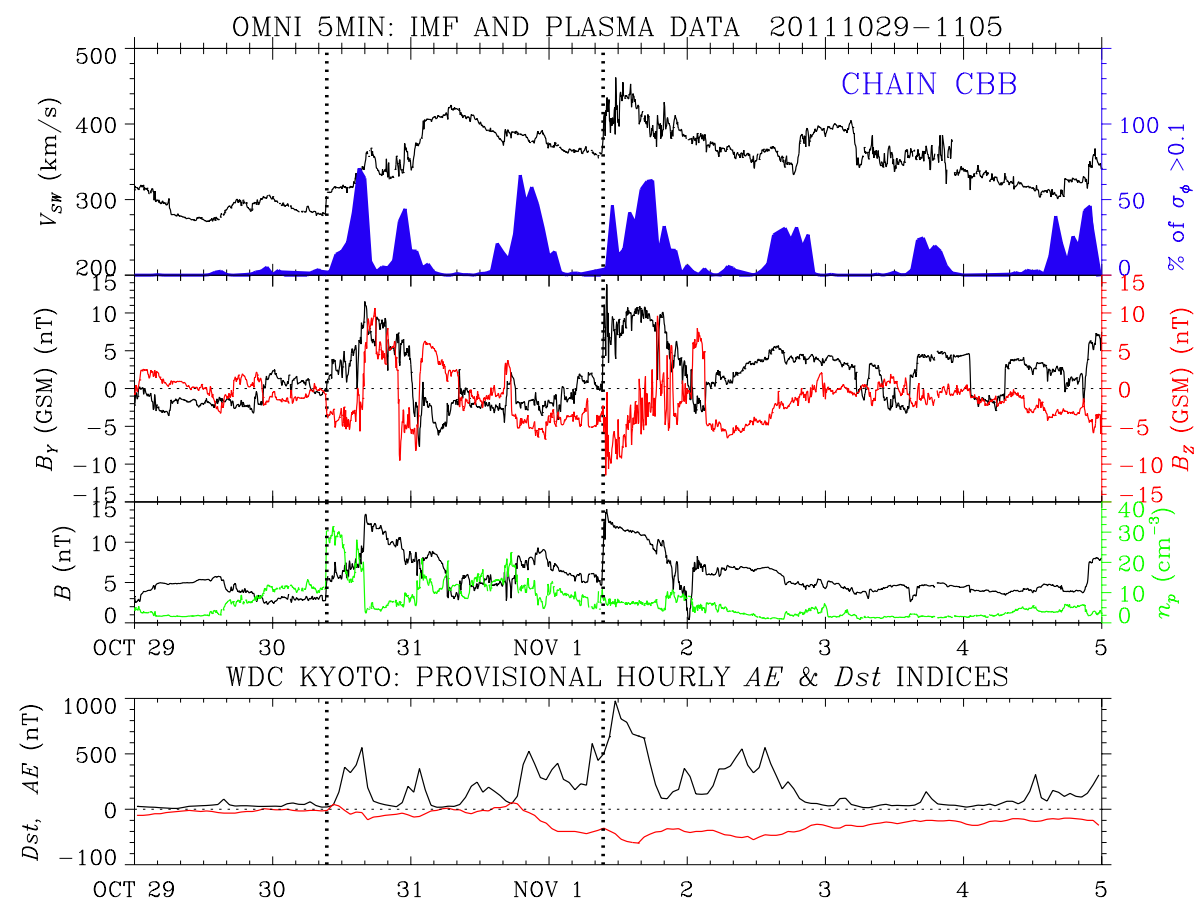

Fig. 2. Solar wind magnetic field and plasma parameters from OMNIWeb dataset. Hourly occurrence of $\sigma_{\Phi}>0.1$ radians from Cambridge Bay is highlighted in blue. Hourly values of AE (black line) and Dst (red line) indices are shown in the bottom panel.

the co-rotating interaction region (CIR) on 30 October. The second upstream shock bounded a sheath of compressed solar wind permeated by an oscillation of predominantly southward IMF $B_{\mathrm{Z}}$. $B$ peaked at $14 \mathrm{nT}$, but then dropped to almost zero (magnetic hole) at 00:00 UT on 2 November followed by relatively constant $B$ of $\sim 4-6 \mathrm{nT}$.

The first ICME shock, which was associated with a southward turning of the IMF, caused the onset of auroral activity and phase scintillation. Figure 2 shows an initial rise in the $\mathrm{AE}$ index correlated with an increase in the occurrence of phase scintillation exceeding 0.1 radians at Cambridge Bay, which was located at the poleward edge of the auroral oval, and observed scintillation primarily in the cusp. As the IMF $B_{\mathrm{Z}}$ switched between southward and northward, the enhancements of $\mathrm{AE}$ index and scintillation occurrence were associated with the southward IMF. The arrival of the second ICME was associated with the strongest southward IMF and resulted in the highest values of $\mathrm{AE}$ and phase scintillation index. A weak geomagnetic storm from the previous day peaked at $\sim 15: 00 \mathrm{UT}(\mathrm{Dst}=-61 \mathrm{nT})$ on 1 November. During the storm recovery phase the scintillation occurrence tapered off staying mostly confined to the cusp and the polar cap as shown below.

Using the altitude adjusted corrected geomagnetic (AACGM) latitude and magnetic local time (MLT) as coordinates, Fig. 3 shows 5-min median-filtered TEC maps (left panels) and mapped HF backscatter line-of-sight velocity (right panels). In Fig. 3a, the TEC map is overlaid with CHAIN stations (red dots), IGS stations (black dots) and ionospheric pierce points (IPPs) at 350-km altitude for cases of phase scintillation $\sigma_{\Phi}>0.1$ radians (open circles) and DPR $>2 \mathrm{~mm} \mathrm{~s}^{-1}$ (crosses). In Fig. 3b, the TEC map is overlaid with the electrostatic potential contours. The drift velocities observed by SuperDARN (Fig. 3d) are used to determine a solution for electrostatic potential expressed as a series expansion in spherical harmonics (Ruohoniemi and Baker, 1998). The line-of-sight velocity maps are overlaid with SuperDARN radar fields of view (Fig. 3c), as well as the electrostatic potential contours (Fig. 3d). Magnetic local noon is toward the top and the night MLT hours are shown at the bottom in each plot.

At 09:30 UT, just after the arrival of the second ICME shock on 1 November, the depressed TEC values indicate that the main ionospheric trough extended at least from 21:00 to 05:00 MLT at mid-latitudes (TEC < 4 TECU). On the dayside, a dense tongue of ionisation (TOI) extended from the sunlit ionosphere along the east coast of Greenland, adjacent to the high-latitude trough (between 70 and $80^{\circ}$ CGM latitudes), and across the pole towards the northwest coast of Canada and Alaska. The Rankin and Inuvik radars observed strong backscatter exceeding $30 \mathrm{~dB}$ (line-of-sight velocities are shown in Fig. 3c) from polar cap patches that originated in the ionospheric cusp footprint located north of Scandinavia, which were also observed by the Hankasalmi radar a few hours earlier (not shown). Over the Canadian Arctic, CHAIN GPS receivers observed intense phase scintillation 
TEC Four Plot GPS Receiver Network (Millstone Hill)

$01 /$ Nov/2011 09:30:00.0 to

$01 /$ Nov/2011 09:35:00.0
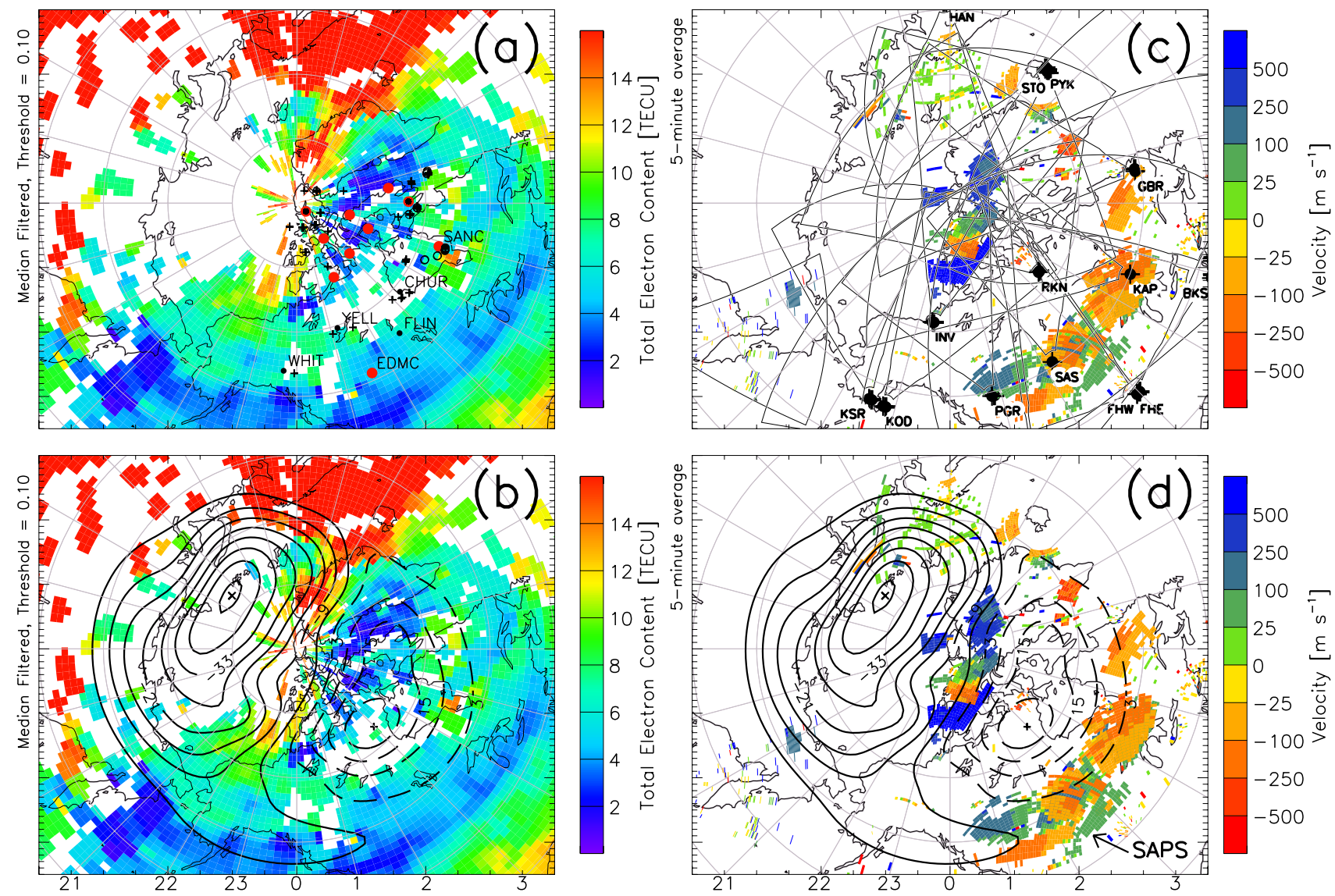

Fig. 3. (a), (b) The 5-min median-filtered TEC mapped in coordinates of CGM latitude and MLT is overlaid (top) with CHAIN (red dots), IGS stations (black dots), IPPs for $\sigma_{\Phi}>0.1$ radians (open circles), DPR $>2 \mathrm{~mm} \mathrm{~s}^{-1}$ (crosses), and (bottom) the SuperDARN potential map. (c), (d) The SuperDARN line-of-sight (LoS) velocities shown in colour on the CGM-MLT grid are overlaid with radar fields of view and the potential map. Blue indicates motion away from the radar and red towards.

that exceeded 1 radian and was caused by polar cap patches that originated from the TOI. The scintillation was observed from Eureka and Resolute Bay at the edge or inside of the TOI as shown by the IPPs for these two stations that are superposed on the TEC map (Fig. 3a).

The ionosondes in Resolute and Eureka observed strong polar patches convecting at velocities reaching up to $1500 \mathrm{~m} \mathrm{~s}^{-1}$ after the arrival of the second ICME. Figure 4 shows a fixed frequency ionogram at $4 \mathrm{MHz}$ from Resolute Bay. A series of patches identified as U-shaped structures were observed during most of the day. The swept-frequency ionograms (not shown) indicated maximum $f o \mathrm{~F} 2$ values up to $\sim 7 \mathrm{MHz}$ in the densest patches. During the period of southward IMF, horizontal drift velocity azimuth was consistently anti-sunward until $\sim$ 19:00 UT when the IMF turned northward and fluctuated (Fig. 2).
Strong HF backscatter was also observed at auroral and sub-auroral latitudes (Fig. 3). The Total Energy Detector (TED) on the NOAA Polar Operational Environment Satellite (POES) system (Evans and Greer, 2000) provides the data used to determine the extent of auroral activity. The instrument monitors the energy fluxes of electrons and positive ions. Figure 5a shows passes of three different POES satellites between 09:00 and 09:35 UT overlaid on the SuperDARN convection map at 09:30 UT. The ionospheric convection in the central polar cap had just started to increase, transporting dense patches of ionisation over Resolute Bay (Fig. 4) from the dayside TOI. A steady but moderate return convection was observed in the midnight-to-dawn sector. The POES pass from 09:00 to 09:20 UT indicated that equatorward boundary of auroral precipitation lay near the Saskatoon radar location (Fig. 5a). Equatorward of it, the Christmas Valley and Fort Hays radars observed westward flows 


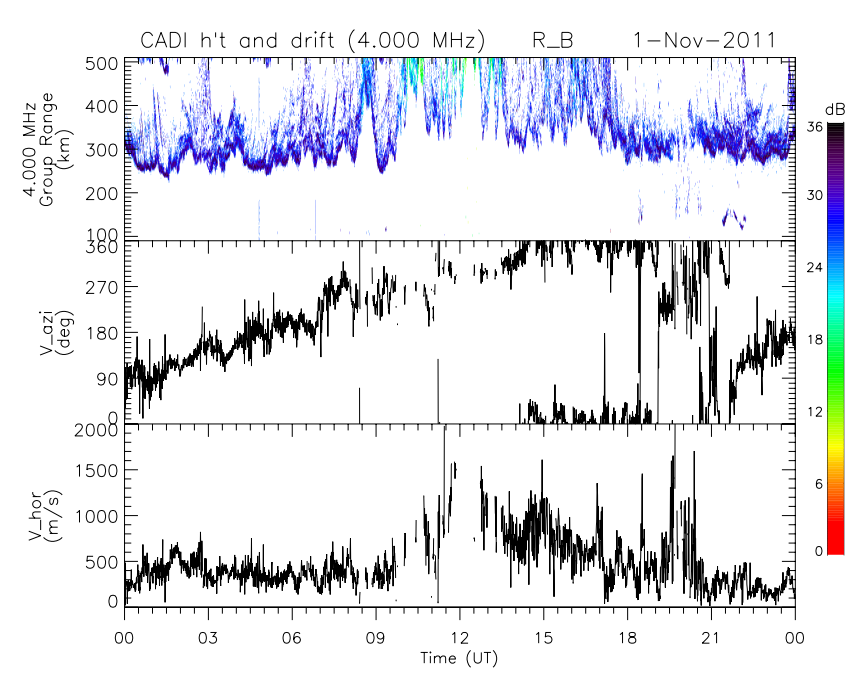

Fig. 4. Fixed frequency ionogram and drift velocity from Resolute Bay on 1 November 2011.

consistent with a moderate sub-auroral polarisation stream (SAPS) (Foster and Burke, 2002; Clausen et al., 2012; Kunduri et al., 2012). Figure 3d shows the SAPS velocities extended along the main trough just south of the radars in Prince George and Saskatoon and adjacent to the CHAIN GPS receiver in Ministik Lake near Edmonton (EDMC in Fig. 1). A weak-to-moderate phase scintillation that was observed at the poleward edge of the mid-latitude trough between 06:00 to 12:00 UT is discussed below.

The SuperDARN convection map at 17:40 UT (Fig. 5b) shows very high ionospheric velocities exceeding $1 \mathrm{~km} \mathrm{~s}^{-1}$ that extended from the cusp deep into the central polar cap where TOI caused intense scintillation. CHAIN (red dots) and IGS stations (black dots) along with IPPs where scintillation index $\sigma_{\Phi}>0.1$ radians (open circles) and/or DPR $>2 \mathrm{~mm} \mathrm{~s}^{-1}$ (crosses) that were observed between 17:40 and 17:42 UT, are superposed. The most intense scintillation showed values of $\sigma_{\Phi}$ exceeding 1 radian. Figure 6 a shows percentage occurrence of phase scintillation $\sigma_{\Phi}$ exceeding 0.1 radians in the Canadian Arctic from 29 October to 4 November, mapped as a function of CGM latitude and universal time (UT) on a grid $1^{\circ} \times 1 \mathrm{~h}$, assuming the ionospheric pierce points (IPP) at $350 \mathrm{~km}$ altitude. Grey areas indicate either complete absence or insufficient number of data points for statistically significant scintillation occurrence in a given grid cell (Spogli et al., 2009). The arrows indicate the arrival times of two ICMEs. The phase scintillation occurrence was significantly enhanced at high latitudes from the auroral oval to polar cap starting on 30 October from $\sim 11$ :00 UT and subsided during the recovery phase of the geomagnetic storm.

Figure $6 \mathrm{~b}$ shows the phase scintillation occurrence maps as a function of magnetic latitude and magnetic local time (MLT) generated for each day separately. The positions of
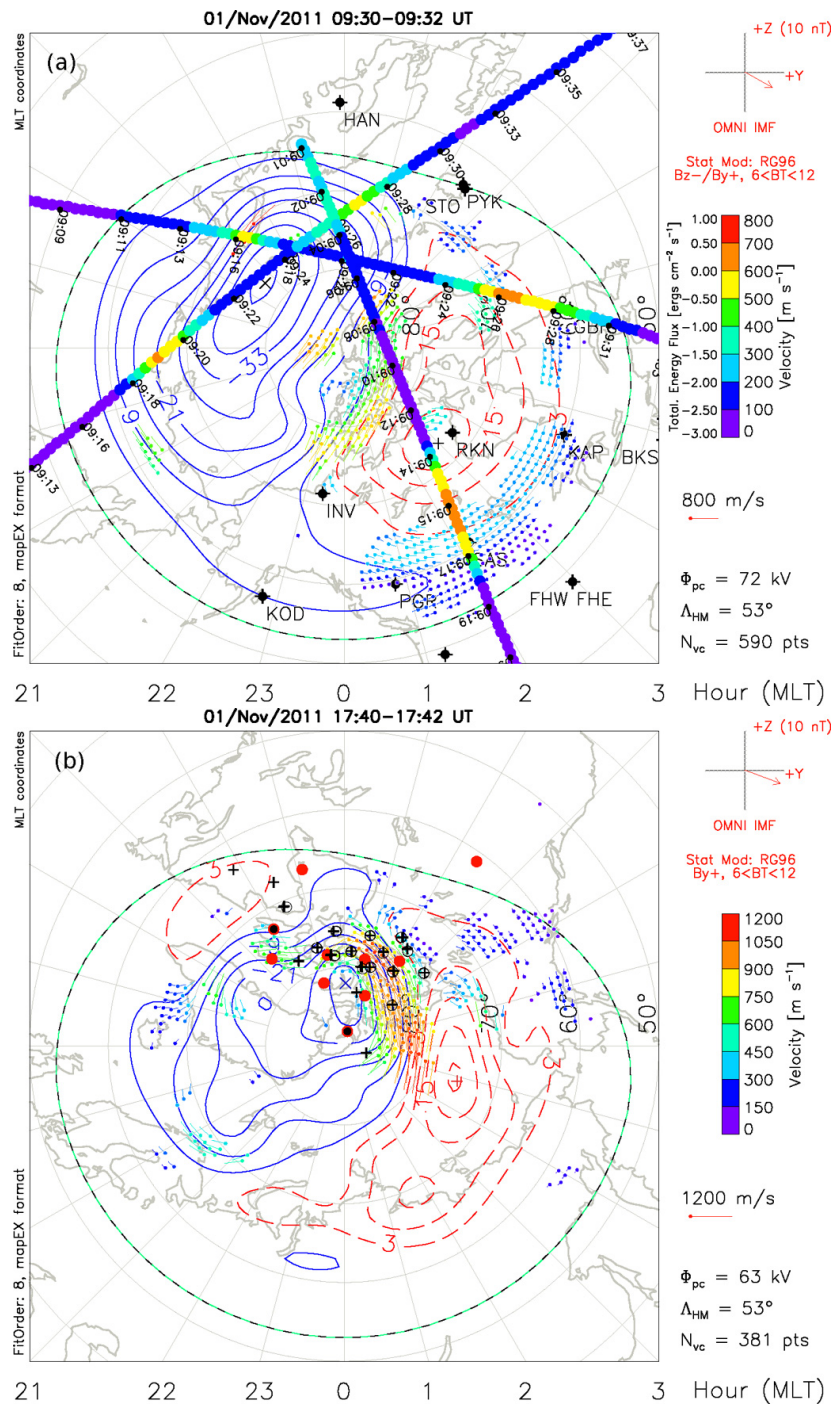

Fig. 5. SuperDARN convection and potential map showing (a) moderate flows in the polar cap and midnight-to-dawn auroral zone, as well as weakened SAPS observed at 09:30 UT overlaid with three passes of POES satellites that observed auroral precipitation between 09:00 and 09:35 UT, and (b) fast convection in the throat region through the cusp where TOI caused intense scintillation. CHAIN (red dots) and IGS stations (black dots) along with IPPs where scintillation index $\sigma_{\Phi}>0.1$ radians (open circles) and/or DPR $>2 \mathrm{~mm} \mathrm{~s}^{-1}$ (crosses) were observed between 17:40 and 17:42 UT, are superposed.

the statistical auroral oval (Feldstein and Starkov, 1967; Holzworth and Meng, 1975) for conditions from very quiet $(I Q=0)$ to disturbed $(I Q=5)$, approximately proportional to daily $\mathrm{Kp}$ index sum ranging from $0+$ to $26+$, are superposed in white line. On each day, the phase scintillation occurrence maximised in the cusp and extended into the polar cap. However, significant scintillation also occurred at auroral and even at sub-auroral latitudes during the most disturbed days. 



Fig. 6. The occurrence of phase scintillation (a), (b) $\sigma_{\Phi}>0.1$ radians, (c) DPR $>2 \mathrm{~mm} \mathrm{~s}^{-1}$ ), (d) Rankin radar backscatter $\left(V_{\mathrm{LOS}}>\right.$ $\left.500 \mathrm{~m} \mathrm{~s}^{-1}\right)$ and (e) Christmas Valley East radar backscatter $\left(V_{\mathrm{LOS}}>100 \mathrm{~m} \mathrm{~s}^{-1}\right)$ from 29 October to 4 November 2011. The maps are shown as a function of CGM latitude and (a) UT or (b)-(e) MLT. White arrows in the top panel indicate the arrival time in UT of two ICMEs. The statistical auroral ovals with IQ values approximately proportional to daily values of Kp index are superposed. 


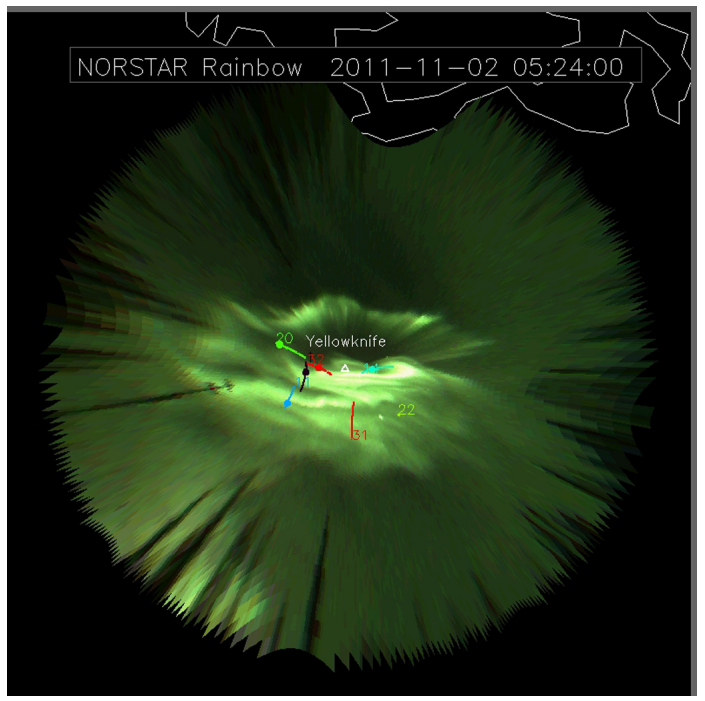

Fig. 7. The auroral emission during an auroral breakup mapped on a geographic grid. The IPPs for GPS satellites at elevation angles above $30^{\circ}$ are superposed for one hour starting at 05:00 UT. The altitude of $110 \mathrm{~km}$ is assumed for both the auroral emission and IPPs. The dots show IPPs at the time when the image was taken, provided that DPR exceeded $4 \mathrm{~mm} \mathrm{~s}^{-1}$. The PRNs are shown and colour-coded as in Fig. 8.

Figure 6c shows the occurrence map of DPR exceeding $2 \mathrm{~mm} \mathrm{~s}^{-1}$. These maps are very similar to the occurrence maps of CHAIN phase scintillation $\sigma_{\Phi}>0.1$ radians (Fig. 6b) although the percentages are higher for the latter threshold. To minimise the multipath effect the phase scintillation index $\sigma_{\Phi}$ and its proxy DPR are obtained for elevations above 30 degrees. Both $\sigma_{\Phi}$ and DPR are projected to the vertical to account for geometrical effects on the measurements made at different elevation angles (Spogli et al., 2009; see their Eq. 1).

The PolarDARN radar in Rankin Inlet (Fig. 1) observed ionospheric backscatter primarily from $\mathrm{F}$ region decameter irregularities in the polar cap (Fig. 3). The occurrence of ionospheric backscatter from irregularities moving at line-ofsight velocity $V_{\mathrm{LOS}}>500 \mathrm{~m} \mathrm{~s}^{-1}$ for beam 6 is mapped as a function of magnetic latitude and MLT (Fig. 6d). In general, the regions of backscatter coincide with both the TOI and the regions of enhanced scintillation. However, because of varied HF propagation conditions and proximity of the Rankin radar to the cusp, strong backscatter that would otherwise coincided with the strongest scintillation could not be observed by the radar.

The MSI radars in Christmas Valley observed the strongest SAPS on 1 November (Fig. 3). The occurrence of ionospheric backscatter from irregularities moving at line-ofsight velocity $V_{\mathrm{LOS}}>100 \mathrm{~m} \mathrm{~s}^{-1}$ for beam 3 of the CV East radar (Fig. 6e) shows a band of high occurrence of subauroral backscatter that is very similar to a band of scintillation observed primarily from Ministik Lake near Edmonton

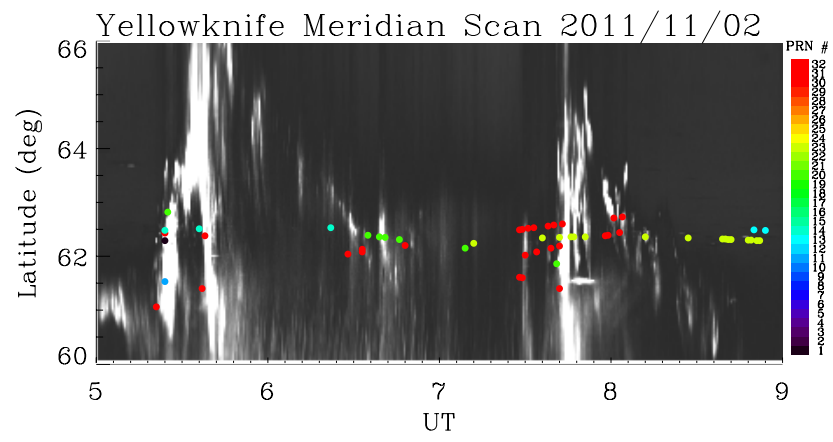

Fig. 8. The meridian scan of auroral intensity as a function of geographic latitude and UT assuming the mapping altitude of $110 \mathrm{~km}$. The IPPs for elevation angles above $30^{\circ}$ and DPR exceeding $4 \mathrm{~mm} \mathrm{~s}^{-1}$ are superposed.

(MST in Fig. 6b). Weak enhancements in DPR index were also observed by $1-\mathrm{Hz}$ receivers in Whitehorse, Saskatoon and Flin Flon but their contributions to the mapped DPR occurrence are smoothed out in Fig. 6c due to many other contributing receivers distributed over a wide range of longitudes where there was no scintillation and the SAPS may not have been present.

The auroral zone was sparsely populated by CHAIN receivers, but they were complemented by the $1-\mathrm{Hz}$ receivers, mostly from IGS stations, which provided the proxy scintillation index. The scintillation in the auroral oval (e.g., Prikryl et al., 2010) is known to be caused primarily by ionospheric irregularities resulting from energetic particle precipitation, which can penetrate deep into the $E$ region and below. In general, the assumption of an E-region altitude for IPP mapping results in co-location of enhanced scintillation with bright auroras (Prikryl et al., 2010).

On 2 November several auroral breakups were observed with an ASI, a riometer and a magnetometer in Yellowknife between 05:00 and 12:00 UT. Figure 7 shows the broadband auroral intensity mapped with geographic projection assuming altitude of $110 \mathrm{~km}$. The superposed line segments show IPPs for GPS satellites at elevation angles above $30^{\circ}$ from the IGS GPS receiver in Yellowknife. The lines have dots where the dots are shown when DPR exceeded a threshold value of $4 \mathrm{~mm} \mathrm{~s}^{\circ}$. The threshold value is doubled to emphasise the close association of the most intense scintillation with auroral breakups and bright auroral arcs. Figure 8 shows a series of meridian scans (a keogram) of the auroral emission as a function of latitude and UT. In general, the scintillation coincided with auroral brightenings although some scintillation persisted even after the aurora moved southward after 08:30 UT.

Figure 9 shows the DPR index, riometer absorption and magnetic field $H$ component perturbations observed in Yellowknife on 2 November. The DPR was enhanced during precipitation events associated with $H$ component perturbations. Also shown is the auroral emission intensity in the 


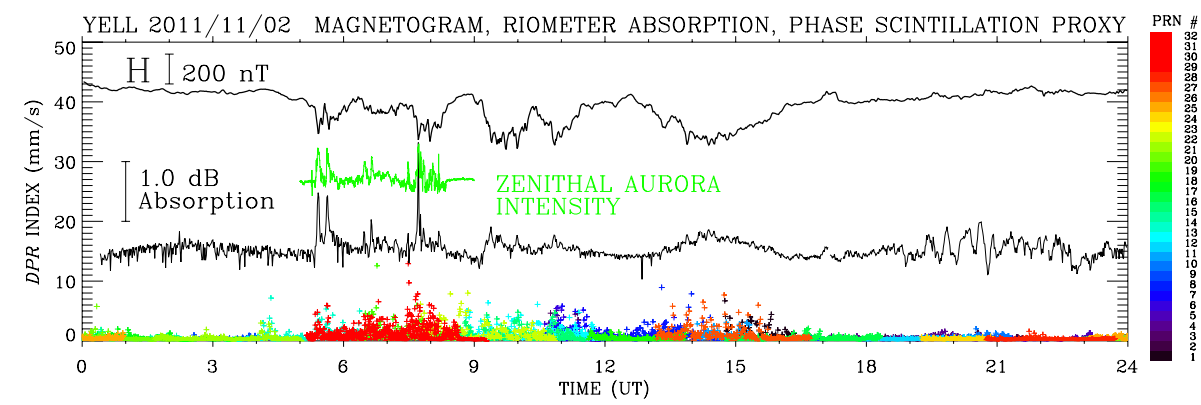

Fig. 9. Phase scintillation proxy index DPR (crosses in colour) for elevations above $30^{\circ}, H$ component of the ground magnetic field and the riometer absorption observed in Yellowknife. Auroral intensity from an approximately 1-km wide pixel in the zenith in relative units is shown in logarithmic scale (green line).

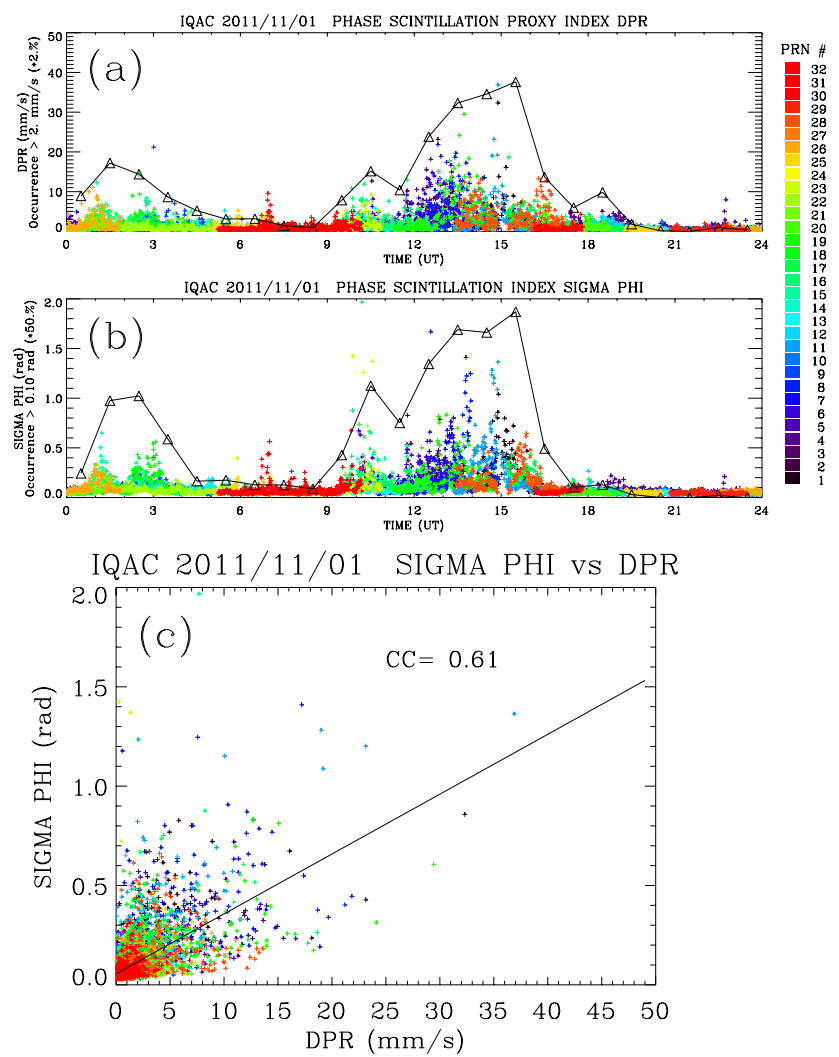

Fig. 10. (a) The proxy DPR index and (b) the 60-s phase scintillation $\sigma_{\Phi}$ for Iqaluit on 1 November 2011. The hourly percentage occurrence of both indices exceeding given threshold values are shown by triangles using a scale with a maximum of $100 \%$ as indicated by scale factors. (c) Scatter plot $\sigma_{\Phi}$ versus DPR showing a moderate correlation between the two indices.

zenith (green line). It can be seen that the cosmic noise absorption (in $\mathrm{dB}$ ) observed by riometers at $30 \mathrm{MHz}$ is a good proxy for precipitating energetic electron fluxes and the auroral emission. The auroral intensity from an approximately $1-\mathrm{km}$ wide pixel in the zenith in relative units is shown using logarithmic scale. The quasi-periodic fluctuations of ri- ometer absorption after 18:00 UT were caused by daytime ionospheric structure imposed by travelling ionospheric disturbances (TIDs) focusing and defocusing the $30 \mathrm{MHz}$ radio waves. Since TIDs are relatively smooth ionospheric structures only very small DPR enhancements between 1 and $2 \mathrm{~mm} \mathrm{~s}^{-1}$ were observed during this time.

\section{A comparison between $\sigma_{\Phi}$ and DPR indices}

Figure $10 \mathrm{a}$ and $\mathrm{b}$ show the 60 -s values of DPR and $\sigma_{\Phi}$, respectively, obtained for the CHAIN GPS receiver in Iqaluit on 1 November 2011. The scatter plot (Fig. 10c) shows that individual values of $\sigma_{\Phi}$ are moderately correlated with DPR (correlation coefficient of 0.61) and the occurrence of phase scintillation in time and PRN number is generally well represented by the DPR proxy index (Fig. 10a). Also, the occurrence of DPR $>2 \mathrm{~mm} \mathrm{~s}^{-1}$ as a function of magnetic latitude and MLT (Fig. 6c) is qualitatively very similar to the occurrence of $\sigma_{\Phi}>0.1$ radians (Fig. 6b). Matching thresholds still need to be determined from a larger data sample. The occurrence maps for both indices clearly show the highest occurrence in the cusp and the polar cap for all days. The scintillation was the strongest in the cusp and the TOI that extended across the polar cap from the dayside to nightside auroral oval on 1 November. Because the ionospheric convection pattern strongly depends on the IMF $B_{\mathrm{y}}$ (Ruohoniemi and Greenwald, 1996), the orientation of the TOI is also determined by the $B_{\mathrm{y}}$ polarity. As shown in Fig. 6, TOI is tilted towards pre-noon hours for most of the days (IMF $B_{\mathrm{y}}>0$ ) except on 29 and 31 October (IMF $\left.B_{\mathrm{y}}<0\right)$.

The scintillation in the auroral oval is known to be caused primarily by steep density gradients and irregularities due to energetic particle precipitation (e.g., Prikryl et al., 2010), which can penetrate deep into the E region and below. The assumption that IPPs are at the E region altitudes results in better alignment or co-location with strong auroral emission (Fig. 8a) than if IPPs are assumed at F-region altitudes. Also, the auroral scintillation is more intermittent, while in the cusp and the polar cap the scintillation can persist for many hours 

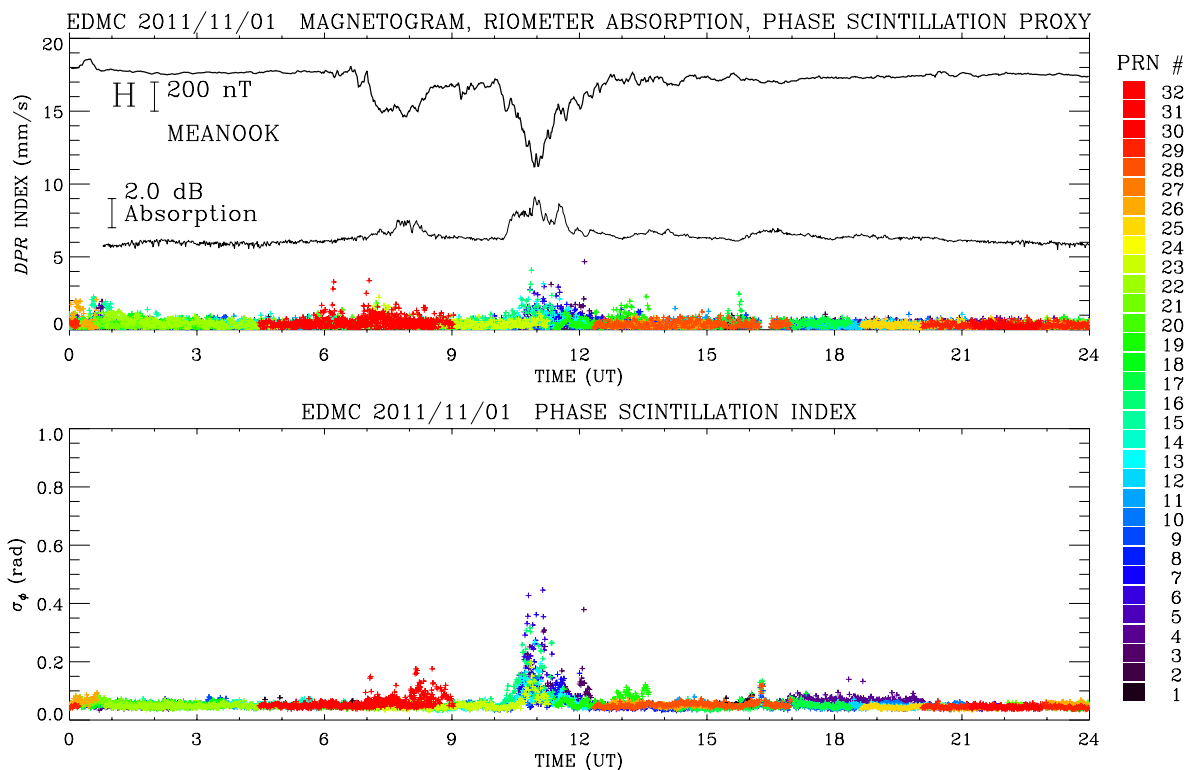

Fig. 11. The proxy DPR index and phase scintillation $\sigma_{\Phi}$ index obtained for elevations above $30^{\circ}$ from GPS receiver in Ministik Lake (EDMC) on 1 November 2011. Superposed in the top panel are the riometer absorption and the $H$ component of the ground magnetic field measured at Meanook.

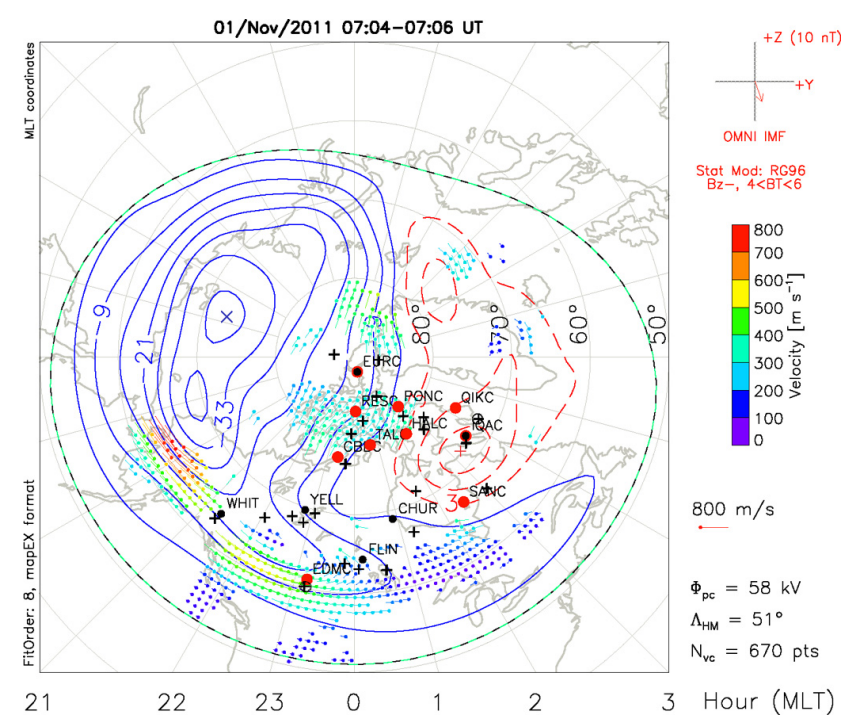

Fig. 12. SuperDARN convection and potential map at 07:04 UT showing the SAPS. The CHAIN stations (red dots) and IGS stations (black dots) with IPPs for $\sigma_{\Phi}>0.1$ radians (open circles) and/or DPR $>2 \mathrm{~mm} \mathrm{~s}^{-1}$ (crosses) are superposed.

(Prikryl et al., 2011), and where the assumption of IPP altitude of $350 \mathrm{~km}$ is more appropriate.

At sub-auroral latitudes, scintillation indices are usually not expected to reach high values. However, the southernmost station of Ministik Lake (EDMC) is suitably located to observe scintillation associated with SAPS. On 1 November, a moderate SAPS was observed by the mid-latitude Su-
perDARN radars (Fig. 3) just south of EDMC receiver that observed $\sigma_{\Phi}$ values exceeding 0.4 radians. A band of weak scintillation occurrence was mapped (Fig. 6b) adjacent to the radar backscatter from fast drifting F-region irregularities (Fig. 6e) just outside of the equatorward border of auroral oval. A couple of 1-Hz GPS receivers around the EDMC region also observed weak enhancements of DPR.

Figure 11 shows the phase scintillation $\sigma_{\Phi}$ and DPR index obtained for elevations above $30^{\circ}$ from EDMC GPS receiver on 1 November 2011. Weak phase scintillation associated with SAPS was observed at the poleward edge of mid-latitude trough (Fig. 3) between 06:00 to 14:00 UT. In general, $\sigma_{\Phi}$ and DPR were correlated, although there were instances of weak scintillation indicated by DPR that were not observed in $\sigma_{\Phi}(\sim 06: 10 \mathrm{UT})$, and instances of low values of $\sigma_{\Phi}$ that when DPR was enhanced ( 08:08 UT), as can be seen in Fig. 11. The observed scintillation coincided with intervals of perturbed magnetic field $H$ component and riometer absorption monitored at Meanook (north of Edmonton). At 07:04 UT, the SuperDARN convection map (Fig. 12) showed SAPS with convection velocities exceeding $500 \mathrm{~m} \mathrm{~s}^{-1}$ over Edmonton. At this time, the EDMC GPS receiver observed a weak phase scintillation event for PRN 32. Both the phase scintillation index $\sigma_{\Phi}$ and its proxy DPR index (Fig. 11) exceeded the thresholds of 0.1 radians and $2 \mathrm{~mm} \mathrm{~s}^{-1}$, respectively.

In summary, it is shown that GNSS data sampled at $1 \mathrm{~Hz}$ can be used to obtain a phase scintillation proxy index to complement the regions with limited geographic coverage by specialised GISTMs. The expanded CHAIN will allow further comparison between $\sigma_{\Phi}$ and DPR, which will help to 
validate the application of the DPR proxy index. The latter could then be used to extend phase scintillation climatology for years before CHAIN operation, as well as include other geographical regions, but is not valid for the case of strong scintillation. If the scintillation proxy index is obtained for the previous solar cycle it could be used to further refine and validate techniques of probabilistic forecasting of phase scintillation (Prikryl et al., 2012).

\section{Conclusions}

Moderate-to-strong phase scintillation was observed at high latitudes during the impacts of two interplanetary coronal mass ejections that resulted in a moderate geomagnetic storm. The scintillation occurrence that was mapped as a function of magnetic latitude and magnetic local time was most intense in the cusp and the polar cap. It coincided with a dense tongue of ionisation (TOI) drawn across the polar cap by intense ionospheric convection, exceeding $1500 \mathrm{~m} \mathrm{~s}^{-1}$ at times. The occurrence maps of phase scintillation $\sigma_{\Phi}$ and its proxy index DPR above given threshold values were similar, thus testing an application of the DPR proxy index to assess the presence of phase scintillation when and where specialised high-rate scintillation receivers are not available. The scintillation was associated with regions of decameter F-region irregularities within TOI and polar cap patches observed by PolarDARN radars and CADI ionosondes. The sub-auroral polarisation stream (SAPS) that was observed with the MSI radars was associated with weak phase scintillation, which mapped along the equatorward border of the auroral oval. The auroral scintillation represented by a proxy index was observed during auroral breakups and was likely caused by E-region electron density irregularities produced by energetic particle precipitation.

Acknowledgements. Infrastructure funding for CHAIN was provided by the Canada Foundation for Innovation and the New Brunswick Innovation Foundation. CHAIN and CGSM operation is conducted in collaboration with the Canadian Space Agency (CSA). The magnetometer and riometer operation and data processing was supported by the Geomagnetic Laboratory, Natural Resources Canada. The operation of the SuperDARN radars in the Northern Hemisphere is supported by the funding agencies of the US, Canada, Japan, UK and France. The funding for the operation of PolarDARN radars was provided by the Natural Sciences and Engineering Research Council of Canada (NSERC) and CSA. The authors from Virginia Tech thank the National Science Foundation for support under grants AGS-0838219 and AGS-0946900. The authors from MIT Haystack also thank the National Science Foundation for support under grant ATM-0856093. EGT acknowledges support provided by the Virginia Space Grant Consortium under a graduate research fellowship. The operation of the SuperDARN radars in the Northern Hemisphere is supported by the funding agencies of US, Canada, UK, France and Japan. International GNSS Service (IGS) and its contributing organisations are thanked for 1-Hz GPS data. The solar wind data were obtained from Goddard Space Flight Center Space Physics Data Facility OMNIWeb (http://omniweb.gsfc.nasa.gov/).

Topical Editor K. Hosokawa thanks P. J. Cilliers and one anonymous referee for their help in evaluating this paper.

\section{References}

Basu, S., Basu, S., MacKenzie, E., and Whitney, H. E.: Morphology of phase and intensity scintillations in the auroral oval and polar cap, Radio Sci., 20, 347-356, doi:10.1029/RS020i003p00347, 1985.

Beach, T. L. and Kintner P. M.: Simultaneous Global Positioning System observations of equatorial scintillations and total electron content fluctuations, J. Geophys. Res., 104, 22553-22565, 1999.

Béniguel, Y., Adam, J.-P., Jakowski, N., Noack, T., Wilken, V., Valette, J.-J., Cueto, M., Bourdillon, A., LassudrieDuchesne, P., and Arbesser-Rastburg, B.: Analysis of scintillation recorded during the PRIS measurement campaign, Radio Sci., 44, RS0A30, doi:10.1029/2008RS004090, 2009.

Chisham, G., Lester, M., Milan, S. E., Freeman, M. P., Bristow, W. A., Grocott, A., McWilliams, K. A., Ruohoniemi, J. M., Yeoman, T. K., Dyson, P. L., Greenwald, R. A., Kikuchi, T., Pinnock, M., Rash, J. P. S., Sato, N., Sofko, G. J., Villain J.-P., and Walker, A. D. M.: A decade of the Super Dual Auroral Radar Network (SuperDARN): Scientific achievements, new techniques and future directions, Survey Geophys., 28, 33-109, doi:10.1007/s10712007-9017-8, 2007.

Clausen, L. B. N., Baker, J. B. H., Ruohoniemi, J. M., Greenwald, R. A., Thomas, E. G., Shepherd, S. G., Talaat, E. R., Bristow, W. A., Zheng, Y., Coster, A. J., and Sazykin, S.: Large-scale observations of a subauroral polarization stream by midlatitude SuperDARN radars: Instantaneous longitudinal velocity variations, J. Geophys. Res., 117, A05306, doi:10.1029/2011JA017232, 2012.

Dandekar, B. S. and Groves, K. M.: Using ionospheric scintillation observations for studying the morphology of equatorial ionospheric bubbles, Radio Sci., 39, RS3010, doi:10.1029/2003RS003020, 2004.

Donovan, E., Trondsen, T., Cogger, L., and Jackel, B.: Auroral imaging within the Canadian CANOPUS and NORSTAR projects, Sodankylä Geophysical Observatory Publications, 92, 109-112, 2003.

Du, J., Caruana, J., Wilkinson, P., Thomas, R., and Cervera, M.: Determination of Equatorial Ionospheric Scintillation S4 by Dual Frequency GPS, Beacon Satellite Symposium, 2001.

Evans, D. S. and Greer, M. S.: Polar orbiting environmental satellite space environment monitor 2: Instrument description and archive data documentation, Tech. Memo., OAR SEC-93, NOAA, Boulder, CO, 2000.

Feldstein, Y. I. and Starkov, G. V.: Dynamics of auroral belt and polar geomagnetic disturbances, Planet. Space Sci., 15, 209-230, 1967.

Foster, J. C. and Burke, W. J.: SAPS: A new categorization for sub-auroral electric fields, Eos Trans. AGU, 83, 393-394, doi:10.1029/2002EO000289, 2002.

Ghoddousi-Fard, R. and Lahaye, F.: Monitoring GPS phase rate variations as a proxy scintillation index, Abstract G012-1465908, GNSS and the Atmosphere, AGU Fall Meeting, San Francisco, 3-7 December 2012. 
Greenwald, R. A., Baker, K. B., Dudeney, J. R., Pinnock, M., Jones, T. B., Thomas, E. C., Villain, J.-P., Cerrisier, J.-C., Senior, C., Hanuise, C., Hunsucker, R. D., Sofko, G., Koehler, J., Nielsen, E., Pellinen, R., Walker, A. D. M., Sato, N., and Yamagishi, H.: DARN/ SUPERDARN A global view of the dynamics of highlatitude convection, Space Sci. Rev., 71, 761-796, 1995.

Holzworth, R. H. and Meng, C.-I.: Mathematical Representation of the Auroral Oval, Geophys. Res. Lett., 2, 377-380, 1975.

Jakowski, N., Borries, C., and Wilken, V.: Introducing a disturbance ionosphere index. Radio Sci., 47, RS0L14, doi:10.1029/2011RS004939, 2012.

Jayachandran, P. T., Langley, R. B., MacDougall, J. W., Mushini, S. C., Pokhotelov, D., Hamza, A. M., Mann, I. R., Milling, D. K., Kale, Z. C., Chadwick, R., Kelly, T., Danskin, D. W., and Carrano, C. S.: Canadian High Arctic Ionospheric Network (CHAIN), Radio Sci., 44, RS0A03, doi:10.1029/2008RS004046, 2009.

Kintner, P. M., Ledvina, B. M., and de Paula, E. R.: GPS and ionospheric scintillations, Space Weather, 5, S09003, doi:10.1029/2006SW000260, 2007.

Kunduri, B. S. R., Baker, J. B. H., Ruohoniemi, J. M., Clausen, L. B. N., Grocott, A., Thomas, E. G., Freeman, M. P., and Talaat, E. R.: An examination of inter-hemispheric conjugacy in a sub-auroral polarisation stream, J. Geophys. Res., 117, A08225, doi:10.1029/2012JA017784, 2012.

Liu, W. W.: Canadian space environment program and international living with a star, Adv. Space Res., 35, 51-60, 2005.

Pi, X., Mannucci, A. J., Lindqwister, U. J., and Ho, C. M.: Monitoring of global ionospheric irregularities using the worldwide GPS network, Geophys. Res. Lett., 24, 2283-2286, 1997.

Prikryl, P., Jayachandran, P. T., Mushini, S. C., Pokhotelov, D., MacDougall, J. W., Donovan, E., Spanswick, E., and St.Maurice, J.-P.: GPS TEC, scintillation and cycle slips observed at high latitudes during solar minimum, Ann. Geophys., 28, $1307-$ 1316, doi:10.5194/angeo-28-1307-2010, 2010.

Prikryl, P., Jayachandran, P. T., Mushini, S. C., and Chadwick, R.: Climatology of GPS phase scintillation and HF radar backscatter for the high-latitude ionosphere under solar minimum conditions, Ann. Geophys., 29, 377-392, doi:10.5194/angeo-29-377-2011, 2011.

Prikryl, P., Jayachandran, P. T., Mushini, S. C., and Richardson, I. G.: Toward the probabilistic forecasting of highlatitude GPS phase scintillation, Space Weather, 10, S08005, doi:10.1029/2012SW000800, 2012.
Prikryl, P., Zhang, Y., Ebihara, Y., Ghoddousi-Fard, R., Jayachandran, P. T., Kinrade, J., Mitchell, C. N., Weatherwax, A. T., Bust, G., Cilliers, P. J., Spogli, L., Alfonsi, L., De Franceschi, G., Romano, V., Ning, B., Li, G., Jarvis, M. J., Danskin, D. W., Spanswick, E., Donovan, E., and Terkildsen, M.: An interhemispheric comparison of GPS phase scintillation with auroral emission observed at South Pole and from DMSP satellite, Ann. Geophys., in preparation, 2013.

Richardson, I. G. and Cane, H. V.: Near-Earth interplanetary coronal mass ejections during solar cycle 23 (1996-2009): Catalog and summary of properties, Solar Phys., 264, 189-237, doi:10.1007/s11207-010-9568-6, 2010.

Rideout, W. and Coster, A.: Automated GPS processing for global total electron content data, GPS Solutions, 10, 219-228, 2006.

Rino, C. L.: A power law phase screen model for ionospheric scintillation 2. Strong scatter, Radio Sci., 14, 1147-1155, doi:10.1029/RS014i006p01147, 1979.

Ruohoniemi, J. M. and Baker, K. B.: Large-scale imaging of highlatitude convection with Super Dual Auroral Radar Network HF radar observations, J. Geophys. Res., 103, 20797-20811, 1998.

Ruohoniemi, J. M. and Greenwald, R. A.: Statistical patterns of high-latitude convection obtained from Goose Bay HF radar observations, J. Geophys. Res., 101, 21743-21763, doi:10.1029/96JA01584, 1996.

Spogli, L., Alfonsi, L., De Franceschi, G., Romano, V., Aquino, M. H. O., and Dodson, A.: Climatology of GPS ionospheric scintillations over high and mid-latitude European regions, Ann. Geophys., 27, 3429-3437, doi:10.5194/angeo-27-3429-2009, 2009.

Thomas, E. G., Baker, J. B. H., Ruohoniemi, J. M., Clausen, L. B. N., Coster, A. J., Foster, J. C., and Erickson P. J.: Direct observations of the role of convection electric field in the formation of a polar tongue of ionization from storm enhanced density, J. Geophys. Res. Space Physics, 118, 1180 1189, doi:10.1002/jgra.50116, 2013.

Van Dierendonck, A. J. and Arbesser-Rastburg, B.: Measuring ionospheric scintillation in the equatorial region over Africa, including measurements from SBAS geostationary satellite signals, Proceeding of ION GNSS 17th technical meeting of the satellite division, Long Beach, CA, 316, 2004.

Yeh, K. C. and Liu, C. H.: Radio wave scintillation in the ionosphere, Proc. IEEE, 70, 324-360, 1982. 